\title{
SPIDIA-RNA: First external quality assessment for the pre-analytical phase of blood samples used for RNA based analyses
}

\author{
M. Pazzagli ${ }^{\text {a,* }}$, F. Malentacchi ${ }^{a}$, L. Simi $^{\text {a }}$, C. Orlando ${ }^{\text {a }}$, R. Wyrich ${ }^{\text {b }}$, K. Günther ${ }^{\text {b }}$, C.C. Hartmann ${ }^{\text {b }}$, \\ P. Verderio ${ }^{c}$, S. Pizzamiglio ${ }^{c}$, C.M. Ciniselli ${ }^{c}$, A. Tichopad ${ }^{\text {de,f }}$, M. Kubista ${ }^{\text {e }}$, S. Gelmini ${ }^{\text {a }}$ \\ a Department of Clinical Physiopathology, University of Florence, Italy \\ ${ }^{\mathrm{b}}$ Qiagen $\mathrm{GmbH}$, Hilden, Germany \\ ${ }^{\mathrm{c}}$ Fondazione IRCCS Istituto Nazionale dei Tumori, Milan, Italy \\ ${ }^{\mathrm{d}}$ Charles University, Pilsen, Czech Republic \\ ${ }^{\mathrm{e}}$ TATAA Biocenter AB, Gothenburg, Sweden \\ ${ }_{\mathrm{f}}^{\mathrm{f}}$ Institute of Biotechnology, Academy of Sciences of the Czech Republic, Prague, Czech Republic
}

\section{A R T I C L E I N F O}

Article history:

Available online $\mathrm{xxxx}$

Communicated by Michael W. Pfaffl

\section{Keywords:}

Pre-analytical phase

RNA quality

Blood samples

External quality assessment

\section{A B S T R A C T}

The diagnostic use of in vitro molecular assays can be limited by the lack of guidelines for collection, handling, stabilization and storage of patient specimens. One of the major goals of the EC funded project SPIDIA (www.spidia.eu) is to develop evidence-based quality guidelines for the pre-analytical phase of blood samples used for molecular testing which requires intracellular RNA analytes. To this end, a survey and a pan-European external quality assessment (EQA) were implemented. This report is the summary of the results of that trial.

With the European Federation of Laboratory Medicine (EFLM) support, 124 applications for participation in the trial were received from 27 different European countries, and 102 laboratories actually participated in the trial. Each participating laboratory described their respective laboratory policies and practices as well as blood collection tubes typically used in performing this type of testing. The participating laboratories received two identical blood specimens: in an EDTA tubes (unstabilized blood; $n=67$ ) or in tubes designed specifically for the stabilization of intracellular RNA in blood (PAXgene ${ }^{\circledR}$ Blood RNA tubes; $n=35$ ). Laboratories were requested to perform RNA extraction according to the laboratory's own procedure as soon as possible upon receipt of the tubes for one tube and $24 \mathrm{~h}$ after the first extraction for the second tube. Participants $(n=93)$ returned the two extracted RNAs to SPIDIA facility for analysis, and provided details about the reagents and protocols they used for the extraction.

At the SPIDIA facility responsible for coordinating the study, the survey data were classified, and the extracted RNA samples were evaluated for purity, yield, integrity, stability, and the presence of interfering substances affecting RT-qPCR assays. All participants received a report comparing the performance of the RNA they submitted to that of the other participants. All the results obtained by participants for each RNA quality parameter were classified as "in control", "warning”, "out of control" and "missing” by consensus mean analysis.

From the survey data, the most variable parameters were the volume of blood collected and the time and storage temperature between blood collection and RNA extraction.

Analyzing the results of quality testing of submitted RNA samples we observed a data distribution of purity, yield, and presence of assay interference in agreement with expected values. The RNA Integrity Number (RIN) values distribution was, on the other hand, much wider than the optimal expected value, which led to an "in control" classification, even for partly degraded RNA samples. On the other hand, RIN values below 5 significantly correlated with a reduction of GAPDH expression levels. Furthermore, the distribution of the values of the four transcripts investigated (c-fos, IL-1 $\beta$, IL-8, and GAPDH) was wide and the RNA instability between samples separated by $24 \mathrm{~h}$ were similar. Assuming the presence of at least two quality parameters "out of control" as an indication of a critical performance of the laboratory, $33 \%$ of the laboratories were included in this group.

The results of this study will be the basis for implementing a second pan-European EQA and the results of both EQAs will be pooled and will provide the basis for the implementation of evidence-based guidelines for the pre-analytical phase of RNA analysis of blood samples.

다 2012 Elsevier Inc. All rights reserved.

\footnotetext{
* Corresponding author. Fax: +39 0554271371.

E-mail address: m.pazzagli@dfc.unifi.it (M. Pazzagli).
} 


\section{Introduction}

SPIDIA (www.spidia.eu) is a 4-year, large-scale, integrated project funded by the European Commission one aim of which is to standardize and improve pre-analytical procedures for in vitro diagnostics by developing quality assurance schemes (EQAs) and validated technologies for the collection, transport and processing of blood samples for RNA-based analyses. Ultimately, the results of these programs will be used as the basis for the development of specimen collection, transport, and handling guidelines for molecular diagnostic testing requiring RNA as the analyte.

Implementing an EQA program for the pre-analytical phase of blood samples collected for RNA based analyses, presents significant challenges. Whole blood is a complex mixture of various cell types in which the relative distribution of white blood cells may differ substantially between normal and diseased subjects. Furthermore gene expression in these cells may be affected by a number of factors that can either induce or repress gene expression changes or lead to degradation of RNA post-phlebotomy [1,2]. As a result of the pilot EQA designed to determine the deficiencies of sample handling for RNA based analyses, we defined the experimental protocol for a larger pan-European EQA [3]. We also proposed a panel of assays to test the quality of the purified RNA derived from blood which included the spectrophotometric measurement of total RNA yield and purity, and the RNA integrity (RIN) score as determined by algorithmic analysis of the RNA electropherogram [4]. Moreover, to test the performance of the resultant RNA in downstream assays, we measured transcript levels of selected genes (c-fos, IL-1 $\beta$, IL-8, and GAPDH) known to be induced or repressed by ex vivo blood handling [3,5-8]. In order to recruit a representative number of participating laboratories, SPIDIA collaborated with the European Federation of Laboratory Medicine (EFLM; www.efcclm.org).

\section{Materials and methods}

\subsection{Collection of applications}

The announcement of the SPIDIA-RNA EQA was published on the EFLM web site (www.efcclm.org). A dedicated website was created which contained the description of the SPIDIA project (www.spidia.eu), the proposed protocols, the application form, and a questionnaire page (www.efcclm.org). Laboratories applying for participation were asked to describe the type of blood collection tube they usually use for RNA based analyses from blood samples: for instance tubes without an RNA stabilizer (e.g. EDTA Tube) or with an RNA stabilizer (e.g. the PAXgene ${ }^{\circledR}$ Blood RNA Tube).

Details on the content of these web pages are reported as Supplemental data: the Questionnaire (Supplement 1), the protocols describing the procedures (Supplements 2 and 3 ) to follow for blood storage/extraction, and the Results form (Supplements 4 and 5) to record the data and information used for blood samples storage/extraction/analysis. Two different protocols and results forms were developed depending on the type of blood collection tube used as specified by the applicant. All participants were informed in advance of the shipping date of the samples.

\subsection{Blood collection and shipment conditions}

Blood was collected from seven, consented healthy donors who were tested negative for HIV, HBV, and HCV. Venous whole blood $(350 \mathrm{ml})$ was collected from each donor into blood collection bags containing citrate phosphate dextrose adenine (CPDA) as the anticoagulant/preservative. Blood from all seven donors was pooled in a sterilized flask, mixed under gently stirring conditions, and immediately aliquoted into $\mathrm{K}_{2}$ EDTA Tubes (Becton Dickinson) ( $5 \mathrm{ml}$ per tube) and PAXgene Blood RNA Tubes (PreAnalytiX) ( $2.5 \mathrm{ml}$ per tube). Participants received a box containing two blood tubes of the same type (labelled Tube $A$ and Tube $B$ ), either $K_{2}$ EDTA or PAXgene Blood RNA tubes and two empty vials to be used to send the extracted RNAs back to the SPIDIA facility for analysis. Boxes were shipped by an international courier the day after blood collection, and blood specimens were stored at $4{ }^{\circ} \mathrm{C}$ prior to packaging and shipment. The boxes contained a frozen soft-gel ice pack to maintain cool conditions during shipping.

\subsection{Instructions for the participants}

The participants received the box containing the blood samples and the protocols (Supplements 2 and 3 ) for performing the RNA extractions. To determine the stability of the RNA in each tube type, the laboratories were instructed, using their standard procedure, to extract RNA from Tube A preferably immediately after the arrival of the samples or at least within $24 \mathrm{~h}$ after arrival, and from Tube B $24 \mathrm{~h}$ after the extraction of Tube A Both Tube A and Tube B were to be stored at $4^{\circ} \mathrm{C}$ prior to RNA extraction. The two extracted RNA samples (RNA A and RNA B) were analyzed spectrophotometrically by the participating laboratory for concentration and purity, and both purified RNA samples were returned to the SPIDIA facility.

\subsection{Data reporting from participants}

The participants recorded in the on-line Results form (Supplements 4 and 5) detailed information about the procedure used during the RNA extraction phase: day of sample arrival, temperature and time of blood sample storage, RNA extraction protocol, spectrophotometric evaluation, and temperature and time of storage of the extracted RNA prior to shipping.

\subsection{Extracted RNA shipment and storage conditions}

After RNA extraction the participants sent the two RNA samples on dry ice back to the SPIDIA facility where the extracted RNA samples were stored at $-80^{\circ} \mathrm{C}$ until analysis.

\subsection{RNA quality parameters}

The RNA quality parameters tested in this study included UV spectrophotometric analysis of RNA purity and yield as determined by the participants as well as the same measurements performed by the SPIDIA facility plus the RIN score (RNA Integrity Number, a software tool designed to estimate the integrity of total RNA sample by the evaluation of the entire electrophoretic trace by Agilent Bioanalyzer 2100, Agilent Technologies) for an overall evaluation of RNA integrity, measurement in RT-qPCR of the expression of cfos, IL-1 $\beta$, IL- 8 and GAPDH transcripts, and kinetics analysis of the RT-qPCR data for the detection of the presence of interfering substances. Details on the reagents and methods used for these analyses are reported elsewhere [3].

\subsection{Statistical analysis and results interpretation}

In the absence of known reference values for each of the factors investigated, we measured the consistency of a given participant's results against all values excluding outliers (90\%) of the results provided by the other participants as described in Orlando et al. [9]. Briefly, a two-step statistical procedure based on a distribution-free approach was adopted in order to process the data corresponding to each of the following variables: RNA purity, RNA yield, RIN, and concentration of transcripts of c-fos, IL- 
$1 \beta$, IL-8, and GAPDH. The aims of this procedure were to detect outliers and/or identify laboratories with issues related to performance.

The first step in the analysis involved the computation of the 95th bootstrap centile [10] of the distribution of the absolute value of the M statistic [11]. This centile was adopted as the threshold for detecting outliers. After removing the outliers from the distribution, the second step was the identification of laboratories whose performance could still be considered as outside the norm of most of the laboratories. This was done by calculating specific bootstrap centiles from the outlier-free distribution. The number of bootstrap samples used was 1000 in each step.

This procedure allowed us to calculate robust control limits (one or two sided) for the evaluation of the performance of each participant. We used the 2.5th and the 97.5th bootstrap centile to identify the lower and upper Action Limit (AL) and the 10th and 90th bootstrap centile to identify the lower and the upper Warning Limit (WL) for all the variables except for "yield" and "RIN", for which higher values indicate better performance. For these two variables we used the 5 th and the 20th bootstrap centile to identify the one-sided $\mathrm{AL}$ and $\mathrm{WL}$, respectively. According to these limits the performance of each participant was classified as follows:

- Out of control: the value exceed the upper or lower AL or the value was below the one-sided AL.

- Warning: the value was between the upper AL and WL or between the lower AL and WL, or between the one-sided WL and AL.

- In control: the value was between the lower and the upper WL, or exceed the one-sided WL.

The analysis and interpretation of the RT-qPCR kinetics were performed as previously described [3].

Panel A

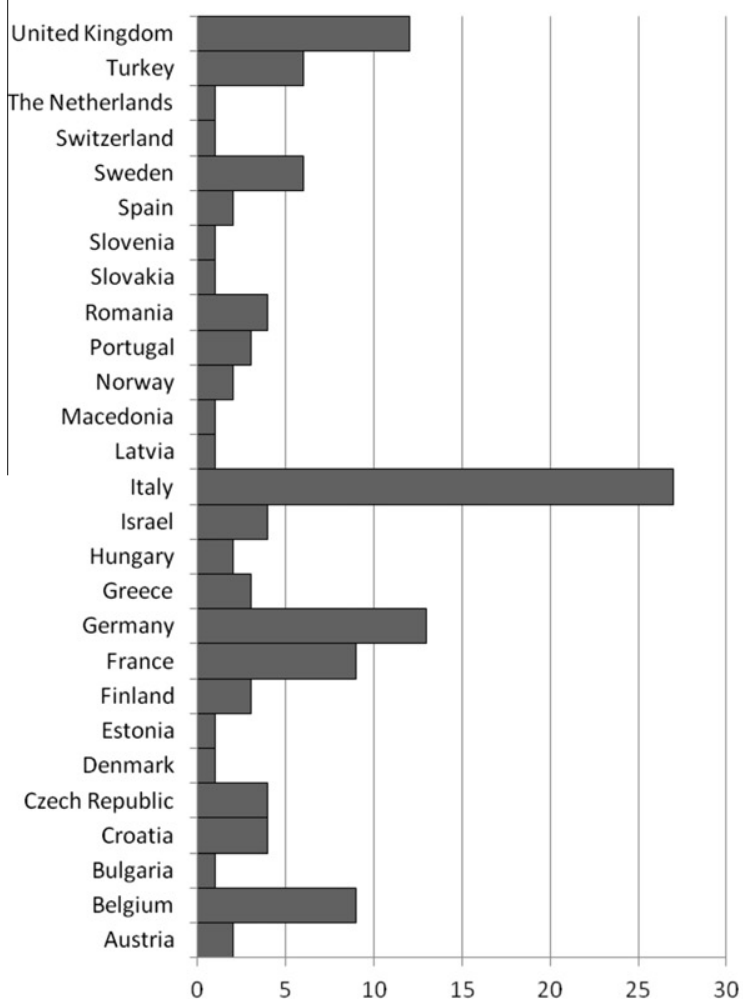

\section{Results}

\subsection{Applicant recruitment and questionnaire information}

One hundred twenty-four (124) applications were received from 27 different European countries, and 102 laboratories confirmed their participation in the first SPIDIA RNA EQA (Fig. 1, Panel A). A description of the structure of the participating laboratories is reported in Fig. 1, Panel B. Main applications for RNA requiring RNA analysis are shown in Fig. 1, Panel C.

At deadline, 93 laboratories (91.1\%) returned extracted RNA to the SPIDIA facility. Sixty-three (63) of the 93 laboratories had received blood specimens in EDTA tubes and the remaining 30 laboratories in PAXgene Blood RNA tubes.

Analysis of the Questionnaire revealed that $65 \%$ of the laboratories typically collect blood in $\mathrm{K}_{2}$ EDTA Tubes, $24 \%$ in PAXgene Blood RNA Tubes, and $11 \%$ in other blood collection tubes. The blood volume normally collected by the participating laboratories ranged from 1.5 to $10 \mathrm{ml}$, and most laboratories perform RNA extraction within $12 \mathrm{~h}$ after blood collection. The extracted RNA is mainly used for RT-qPCR/RT-PCR analysis. These data and additional information about the current methods for RNA extraction and evaluation of RNA concentration are summarized in Table 1.

\subsection{Report for the participants}

At the SPIDIA facility, the extracted RNA samples were analyzed as reported in Section 2, and the results evaluated using the statistical approach described above to produce an individual report for each participant (see example in Appendix A). In the report, the distribution of all the data for each quality parameter is graphically displayed in a box-plot which included the AL and the WL together with a red dot indicating the individual value of the particular laboratory. A red box under each graph indicated the classification of
Panel B
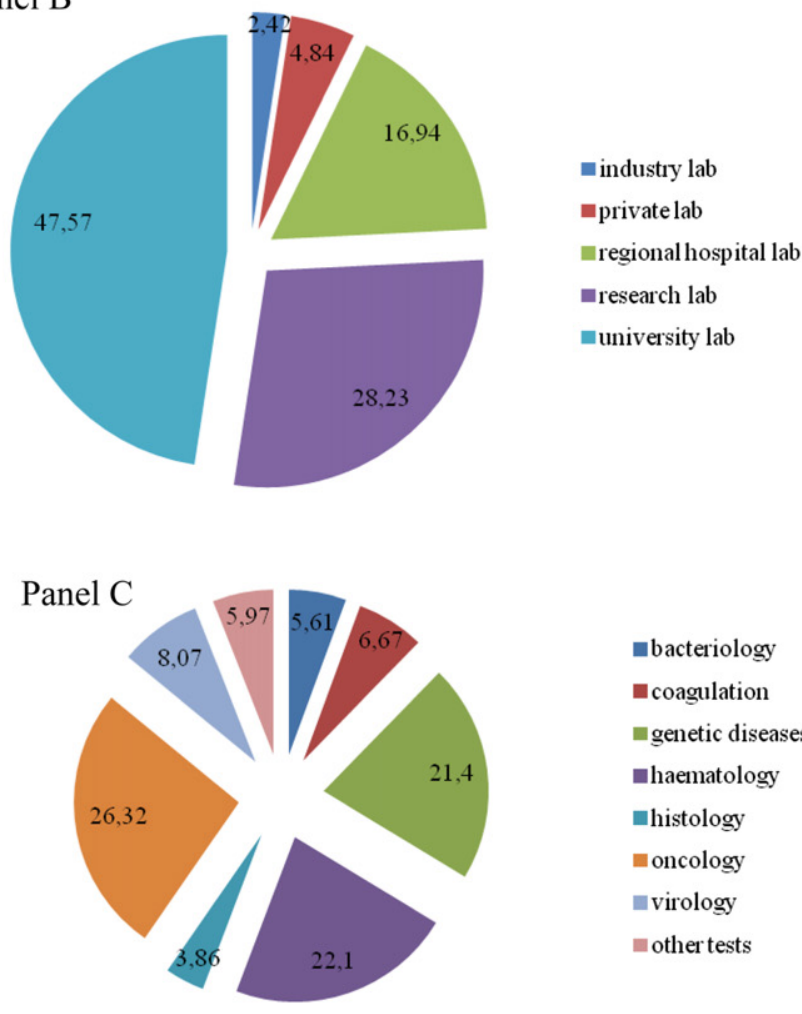

abacteriology

coagulation

menetic diseases

- haematology

- histology

ancology

virology

ather tests

Fig. 1. Distribution of participant laboratories $(n=124)$ through Europe (Panel A), affiliation (Panel B) and the main area of research (Panel C). 
Table 1

QUESTIONNAIRE distribution frequencies: usual procedures used by participant labs $\left(N=92^{\mathrm{a}}\right)$.

\begin{tabular}{|c|c|c|c|}
\hline Questions & & $N$ & $\%$ \\
\hline \multirow[t]{5}{*}{ 1. In which tube do you usually perform blood collection? } & $\mathrm{K}_{2}$ EDTA & 60 & 65.22 \\
\hline & NaCitrate & 2 & 2.17 \\
\hline & LiEparine & 1 & 1.09 \\
\hline & PAXgene blood RNA tube & 22 & 23.91 \\
\hline & Other & 7 & 7.61 \\
\hline \multirow[t]{4}{*}{ 2. How many milliliters of blood do you collect? } & $1.5 \mathrm{ml}<\mathrm{ml}<2.5 \mathrm{ml}$ & 6 & 6.52 \\
\hline & $2.5 \mathrm{ml} \leqslant \mathrm{ml}<5 \mathrm{ml}$ & 41 & 44.57 \\
\hline & $5 \mathrm{ml} \leqslant \mathrm{ml} \leqslant 10 \mathrm{ml}$ & 38 & 41.30 \\
\hline & $>10 \mathrm{ml}$ & 7 & 7.61 \\
\hline \multirow{3}{*}{$\begin{array}{l}\text { 3. How long is the time interval between the } \\
\text { blood collection and the RNA extraction? }\end{array}$} & $\leqslant 12 \mathrm{~h}$ & 50 & 54.35 \\
\hline & $12 \mathrm{~h}<\mathrm{h} \leqslant 24 \mathrm{~h}$ & 29 & 31.52 \\
\hline & $>24 \mathrm{~h}$ & 13 & 14.13 \\
\hline \multirow[t]{4}{*}{ 4. At what temperature is stored the collected blood? } & $-80^{\circ} \mathrm{C}$ & 9 & 9.78 \\
\hline & $-20^{\circ} \mathrm{C}$ & 11 & 11.96 \\
\hline & $4^{\circ} \mathrm{C}$ & 48 & 52.17 \\
\hline & Room temperature & 24 & 26.09 \\
\hline \multicolumn{4}{|l|}{ 5. What is the procedure for RNA extraction? } \\
\hline Do you use a kit? & Yes & 77 & 83.70 \\
\hline The method to isolated RNA is based on... & No & 15 & 16.30 \\
\hline Silica membrane & & 63 & 81.82 \\
\hline Magnetic beads & & 3 & 3.90 \\
\hline Precipitation & & 6 & 7.79 \\
\hline Not available & & 5 & 6.49 \\
\hline \multirow{3}{*}{$\begin{array}{l}\text { 6. How many microliters do you use to resuspend/elute } \\
\text { the extracted RNA from blood? }\end{array}$} & $\leqslant 50 \mu \mathrm{l}$ & 60 & 65.22 \\
\hline & $50 \mu \mathrm{l}<\mu \mathrm{l} \leqslant 100 \mu \mathrm{l}$ & 26 & 28.26 \\
\hline & $>100 \mu \mathrm{l}$ & 6 & 6.52 \\
\hline \multicolumn{4}{|l|}{ 7. Do you evaluate the concentration of extracted RNA? } \\
\hline \multirow[t]{8}{*}{ What is the method? } & Yes & 81 & 88.04 \\
\hline & No & 11 & 11.96 \\
\hline & Spectrophotometer & 61 & 75.31 \\
\hline & Agilent Bioanalyzer & 1 & 1.24 \\
\hline & PicoGreen & 1 & 1.24 \\
\hline & Other & 5 & 6.17 \\
\hline & Agilent + other & 1 & 1.24 \\
\hline & Spectrophotometer + Bioanalyzer + other & 12 & 14.80 \\
\hline \multirow{3}{*}{$\begin{array}{l}\text { 8. How long is the time interval between the RNA extraction } \\
\text { and concentration evaluation? }\end{array}$} & $\leqslant 6 \mathrm{~h}$ & 78 & 84.78 \\
\hline & $6 \mathrm{~h}<\mathrm{h} \leqslant 24 \mathrm{~h}$ & 12 & 13.04 \\
\hline & $>24 \mathrm{~h}$ & 2 & 2.17 \\
\hline \multirow{11}{*}{$\begin{array}{l}\text { 9. What kind of analysis do you usually perform on your extracted } \\
\text { (multiple answers) }\end{array}$} & & & \\
\hline & rt-PCR & 7 & 7.61 \\
\hline & rt-qPCR & 35 & 38.04 \\
\hline & microarray & 1 & 1.09 \\
\hline & rt-PCR + rt-qPCR & 34 & 36.96 \\
\hline & RIN + rt-qPCR & 6 & 6.52 \\
\hline & RIN + rt-PCR + rt-qPCR & 3 & 3.26 \\
\hline & RIN + microarray & 1 & 1.09 \\
\hline & rt-PCR + microarray & 1 & 1.09 \\
\hline & RIN + rt-qPCR + microarray & 3 & 3.26 \\
\hline & rt-PCR + rt-qPCR + microarray & 1 & 1.09 \\
\hline \multirow{4}{*}{$\begin{array}{l}\text { 10. How long is the time interval between the RNA } \\
\text { extraction and the analysis of RNA? }\end{array}$} & $\leqslant 6 \mathrm{~h}$ & 21 & 22.83 \\
\hline & $6 \mathrm{~h}<\mathrm{h} \leqslant 24 \mathrm{~h}$ & 39 & 42.39 \\
\hline & $24 \mathrm{~h}<\mathrm{h} \leqslant 120 \mathrm{~h}$ & 23 & 25.00 \\
\hline & $>120 \mathrm{~h}$ & 9 & 9.78 \\
\hline \multirow[t]{2}{*}{ 11. At what temperature do you usually store the extracted RNA? } & $-80^{\circ} \mathrm{C}$ & 77 & 83.70 \\
\hline & $-20^{\circ} \mathrm{C}$ & 15 & 16.30 \\
\hline \multirow[t]{4}{*}{ 12. For how long time do you usually store RNA? } & No storage & 3 & 3.26 \\
\hline & Days & 4 & 4.35 \\
\hline & Months & 8 & 8.69 \\
\hline & Years & 77 & 83.70 \\
\hline
\end{tabular}

${ }^{a}$ One participant did not answer to the questionnaire.

the laboratory's performance for this specific parameter. A zoom window was also displayed for each box-plot to aid visualization of the participant's result when the distribution of the variables was highly skewed.

\subsubsection{Spectrophotometric data}

Tables A.1 and A.2 summarize the spectrophotometric measurement results provided by the participants along with some details concerning times, methods, and reagents used by each participant. Sections A.3 and A.4 show box-plots of the distributions of RNA yield and purity reported by the participants in the Results form for the two extracted blood samples.

For purity (A.3), the median value and inter-quartile range (IQR) are similar for RNA A and RNA B (median RNA A: 1.97, median RNA B: 2.00 , IQR RNA A 0.20 , and IQR RNA B 0.20). The warning limits indicate that the performance of a laboratory can be classified as 
being in control with respect to the results of the other participants (having excluded outliers) if their reported purity values are in the range 1.7-2.1.

For total RNA yield (ng/ $\mu$ l blood) (A.4), the distribution of RNA A yields is broader than that of RNA B due to outlier values. The median values and the control limits of the two RNAs, however, are similar because computation of these numbers is not influenced by outlier values. The median yield of RNA A is $2.23 \mathrm{ng} / \mu \mathrm{l}$ blood and of RNA B it is $2.25 \mathrm{ng} / \mu \mathrm{l}$ blood, and the IQR's are very similar: 2.07 for RNA A and 1.82 for RNA B. The warning limits indicate that the performance of a specific laboratory can be classified in control with respect to the results of the majority of participants if the measured RNA total yield is more than about $1.00 \mathrm{ng} / \mu \mathrm{l}$ of blood for both RNA A and B.

\subsubsection{RIN value}

Section B. 1 reports the distributions of the RIN values measured on the two RNA samples extracted by the participants. Due to atypical electropherograms observed for several of the extracted RNA samples, the evaluation of RIN values was possible only for 77 RNA $A$ and 78 RNA B samples. The median value was similar for the two RNAs (median RNA A 7.6 and RNA B 7.4), while the variability represented by the IQR was higher in RNA B $(I Q R=4.2)$ than for RNA A $(I Q R=3.5)$. The limits calculated (B.1) indicate that the performance of a specific laboratory can be classified in control with respect to the results of the majority of the participants when the RIN value is greater than approximately 4 for RNA A as well as RNA B.

The electropherograms of the RNA integrity analysis for RNA A and $\mathrm{B}$ are reported in Section B.2.

Finally, to explore the association between RNA integrity and gene expression on our data, we dichotomized the continuous variable RIN according to the cut-off value of 5 as suggested by Fleige et al. $[17,18]$. The box plots in Fig. 2, obtained by considering the GAPDH expression, are representative of the decreasing trend in expression that we observed, regardless of the statistical significance, for all the other three considered genes (data not shown).

\subsubsection{Gene expression profile}

The distributions of the gene expression $\left[\log _{10}\right.$ (copies/ $\mu$ g total RNA)] of the four genes tested are graphically represented in Sections C. 1 and C.2. The distributions of the expression levels for all the gene transcripts are similar in RNA A and RNA B.

\subsubsection{Real time PCR kinetics analysis}

Sections D. 1 and D.2 report the distribution of the kinetics distance (Kd) obtained by the analysis of the qPCR kinetics data with

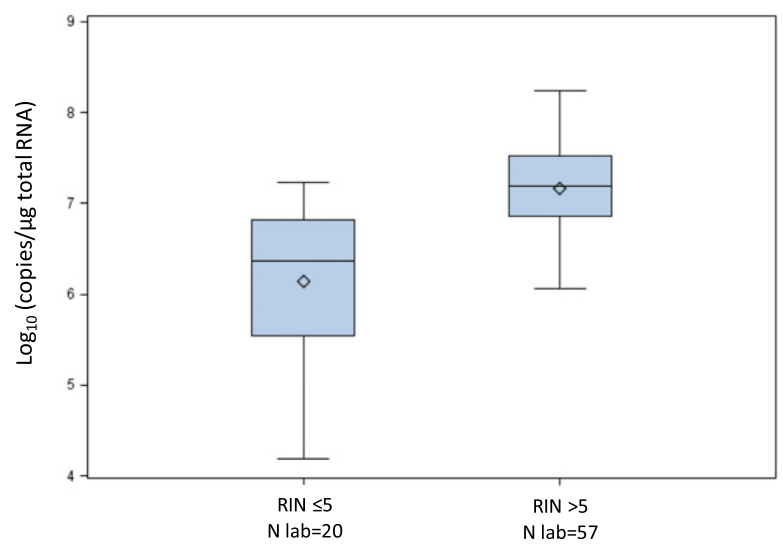

Fig. 2. GAPDH expression in RNA A and RIN variable dichotomized according to the cut-off value of 5 ( $\mathrm{N} \mathrm{lab}=20$ for RIN $\leqslant 5 ; \mathrm{N} \mathrm{lab}=57$ for RIN $>5$; Kruskal-Wallis test, $p<0.0001)$.
Table 2

Classification of the performance of the laboratories.

\begin{tabular}{lcc}
\hline Categories & N & \multicolumn{2}{l}{} \\
\hline All in control or warning performance & 24 & 25.81 \\
One out of control performance and/or one or more missing & 38 & 40.86 \\
Two or more out of control performance with or without & 31 & 33.33 \\
$\quad$ missing & 93 & 100.00 \\
Total & &
\end{tabular}

Description of the categories:

- all in control or warning performance: labs with all performances in control or warning, without missing;

- one out of control performance and/or one or more missing: labs with only one out of control $(N=12)$; labs with only one missing $(N=7)$ or only more than one missing $(N=7)$; labs with one out of control and one missing $(N=8)$; labs with one out of control and more than one missing $(N=4)$;

- two or more out of control performance with or without missing: labs with two out of control with at least one missing $(N=8)$ or without missing $(N=4)$; labs with more than two out of control with at least one missing $(N=11)$ or without miss$\operatorname{ing}(N=8)$.

the Kineret software described by Tichopad et al. [12]. The two lines depicted in the figures correspond to the theoretical limits used to detect strong (>9.21) and weak outliers (5.99-9.21). For all transcripts the median value is below the defined thresholds. Only for GAPDH were no outliers observed.

\subsubsection{Summary of the lab performance evaluation}

Table E (Appendix A) summarizes the performance of the laboratories for the evaluated RNA quality parameters. The table shows the results using three colors: green if the performance is "in control", yellow if the performance is "warning" or "weak outlier", and red if the performance is "out of control" or "strong outlier". When it was not possible to evaluate the performance due to a missing value, "missing" is reported in the summary table with an explanation in the "comments" column. All data are visually summarized as a radar graph with performance symbolized by a colored square (same colors as in the summary table) and the distance between the colored square and the center of the radar indicates the performance (further away from the center, the worse is the performance).

\subsection{Overall performance of the laboratories participating in the RNA SPIDIA EQA program}

On the basis of the RNA quality parameters and of the statistical approach used in this EQA program, for 24/93 laboratories (26\%) the performance was not critical (all parameters classified as "in control" or "warning"). For 38/93 (41\%) laboratories only one quality parameter was "out of control" (plus possibly one or more missing data point). For the remaining 31/93 (33\%) laboratories two or more "out of control" quality parameters were noted, plus possibly one or more missing data points (see Table 2).

\section{Discussion}

Molecular methods are today widely used in laboratory medicine. For genomics analysis in the last few years, it has been possible to implement an adequate quality assurance framework. This is based on knowledge acquired from specific surveys [13], the implementation of quality assurance and proficiency programs (www.cap.org; www.emqn.org; www.dgkl.dc; www.eurogentest.org), and by the development of dedicated guidelines [14].

For transcriptome analysis, the situation is different. Due to the well known intrinsic instability of RNA and therefore the critical role the pre-analytical phase plays in RNA analysis, there is a much higher level of complexity of factors that affect accurate results. Only a few surveys and EQA programs have been implemented $[9,15,16]$, and the quality of assays is currently not monitored. 
One aim of the EU granted project SPIDIA is to develop evidence-based guidelines and quality assurance schemes for the collection, transportation and processing of blood samples for RNAbased analysis. As one step towards this goal, a survey and a proficiency testing program has been implemented to evaluate current sample technologies for RNA-based analysis from blood among routine laboratories in Europe.

The survey asked questions about what sorts of laboratory policies and practices are in place (Fig. 1) for specimen handling, and respondents were requested to provide information on aspects related to blood sampling and extraction protocols (Table 1). A clear tendency to use commercially available extraction kits (predominantly using silica membrane technology) was noted. The vast majority of the laboratories performed the evaluation of yield and quality of RNA by UV analysis and stored extracted RNA at $-80^{\circ} \mathrm{C}$. The dominant downstream analytical methods were PCR technologies (qualitative and quantitative RT-PCR). Other aspects of sample handling and analysis protocols were more variable, such as the volume of blood used and the kind of collection tube, time and storage temperature between blood collection and RNA extraction and analysis. The wide range of answers to these questions confirmed the need to develop guidelines for this area of analysis.

Together with the survey, SPIDIA also implemented an EQA program focused on the pre-analytical phase of analyzing RNA in blood. Details on the experimental set-up and the RNA quality parameters used in this EQA were investigated in a pilot study and have been reported elsewhere [3].

Using this approach, we have evaluated the quality of RNA extracted by the participants and produced an individual report describing the performance of the laboratory classified in respect to the results of the majority of participants. Looking at the distribution of the results obtained by the participants (see the report in Appendix A), we observed a median value of measured RNA purity close to 2.0 for both RNA A and RNA B, which is typical for high quality RNA $[17,18]$. The median RNA yield was about $2 \mathrm{ng} / \mu \mathrm{l}$ blood. The $\mathrm{AL}$ and WL of the RIN values were 2.61 and 4.77 for RNA A (median 7.6) and 2.49 and 4.25 for RNA B (median 7.4), respectively. Fleige et al. [18] report that a RIN value higher than 8 corresponds to high quality total RNA, while a RIN value between 5 and 8 reflects partly degraded RNA. According to the experimental model and statistical analysis proposed in this study, we classified "in control" some RNA samples that according to Fleige et al., should be considered "partly degraded". This is not an inconsistency for three reasons. First, we defined valid result based on consensus with all testing participants' results and not by comparison to any absolute target, Second, participants' RNA samples were obtained by different extraction procedures, and Third, the survey material may have been heterogeneous at the time of extraction due to other pre-analytical variables (time and temperature of shipment/storage).

Following the RIN cut-off reported by Fleige et al. we categorized the RNA A samples and analyzed the gene expression of the four target genes; all of them showed an expression decreased in samples with RIN below 5 . This trend underlines the relevance of the RIN in gene expression studies: RIN under 5 can induce misleading in the gene expression evaluation, even if the amplicon length is less than $130 \mathrm{bp}$.
The distribution of the expression levels of the four gene transcripts investigated as well as the Kd values obtained from the Kineret analysis are similar in RNA A and RNA B. Taken together, these data show reliable values for the RNA quality parameters, but we must emphasize that they were obtained without considering the missing data and after removing outliers. For example, statistical analysis of RIN score data, only $82 \%$ of all of the samples returned by participating laboratories were considered because of aberrant electropherograms.

Analysis of individual reports of the participants after the assessment of the performance of the laboratories participating in the SPIDIA EQA program. revealed that 31/93 laboratories (about $33 \%$ ) had at least two quality parameters "out of control" and only $24 / 93$ (26\%) of the laboratories had a "not critical" ("in control" or "warning") assessment for all the considered quality parameters.

The goal of this first SPIDIA-RNA EQA was to gather and collate information on resulting RNA quality when the participants followed the protocols and reagents in use in their laboratories. Due to the high variability in protocols and reagents used by the laboratories that received an EDTA tube, it was not possible to further analyze the data of this survey with regard to the impact on a single quality parameter of certain sample preparation methods and the time interval between collection and extraction. Direct comparisons of individual quality parameter of the laboratories that used the PAXgene Blood RNA tubes and the laboratories that received EDTA tubes are in process.

As mentioned earlier, gene expression stability is a prerequisite for good performance of the isolated RNA in RNA based analytical methods, and the use of blood collection tubes without stabilizer can lead to artificially induced post sampling gene expression changes for certain genes [5-8]. A more detailed analysis of the different sample collection technologies will be necessary to investigate and compare the results from the laboratories that received the PAXgene Blood RNA tubes to those who received EDTA tubes to answer whether the use of a blood RNA stabilization technology improves the results of RNA based analysis from blood samples.

In preparation for the second SPIDIA-RNA EQA, we have performed additional studies on a small scale to further optimize the protocols for the implementation of this next step. The use of improved protocols for blood collection and shipment, together with more rigorous and defined protocols for the participants is expected to allow a more in-depth analysis of the critical steps of the pre-analytical phase which will allow for the development of evidence-based quality guidelines.

\section{Acknowledgements}

Grant/funding support. The SPIDIA RNA study has been supported by European Union (FP7. Title "SPIDIA: Standardization and improvement of generic pre-analytical tools and procedures for in vitro diagnostic", Grant agreement no. 222916).

We acknowledge Labonnet Ltd. Company for providing the Kineret software.

We gratefully acknowledge the contribution of all partners and participant laboratories.

We are very grateful to Lynne Rainen for the scientific contribution and language editing of this manuscript.

\section{Appendix A. Purity and Quantity of RNA A and RNA B.}

\section{A.1. Spectrophotometric data provided by your lab}

\begin{tabular}{|c|c|c|c|c|c|c|c|c|c|}
\hline Sample & $260 \mathrm{~nm}$ & $280 \mathrm{~nm}$ & $320 \mathrm{~nm}$ & Purity & Quantity (ng/ $\mu$ l blood) & Dilution factor & Extraction vol. $(\mu \mathrm{l})$ & Elution vol. $(\mu \mathrm{l})$ & Buffer \\
\hline RNA A & 0.051 & 0.025 & 0.001 & 2.083 & 0.600 & 1 & 5000 & 30 & - \\
\hline RNA B & 0.114 & 0.055 & 0.000 & 2.073 & 1.368 & 1 & 5000 & 30 & - \\
\hline
\end{tabular}


A.2. Additional information provided by your lab

\begin{tabular}{|c|c|c|c|c|c|c|c|c|}
\hline \multirow[t]{2}{*}{ Sample } & \multicolumn{2}{|c|}{ Time interval (hours) } & \multicolumn{2}{|c|}{ Temperature of RNA storage } & \multicolumn{2}{|c|}{ Extraction } & \multicolumn{2}{|c|}{ Spectrophotometer } \\
\hline & $\begin{array}{l}\text { Arrival to } \\
\text { extraction }\end{array}$ & $\begin{array}{l}\text { Extraction to } \\
\text { analysis }\end{array}$ & $\begin{array}{l}\text { Arrival to } \\
\text { extraction }\end{array}$ & $\begin{array}{l}\text { Extraction to } \\
\text { analysis }\end{array}$ & Producer & Supplier & Producer & Supplier \\
\hline RNA A & $4.75 \mathrm{~h}$ & $164.00 \mathrm{~h}$ & $4^{\circ} \mathrm{C}$ & $-20^{\circ} \mathrm{C}$ & Qiagen & $\begin{array}{l}\text { 74134/RNeasy } \\
\text { Plus Mini kit }\end{array}$ & IMPLEM & Nanophotometer \\
\hline RNA B & $28.75 \mathrm{~h}$ & $140.00 \mathrm{~h}$ & $4^{\circ} \mathrm{C}$ & $-20^{\circ} \mathrm{C}$ & & & & \\
\hline
\end{tabular}

\section{A.3. Your lab (๑) versus overall distribution - Purity}

In the figures the blue lines represent the Action Limits (ALs) and the gray lines represent the Warning Limits (WLs).
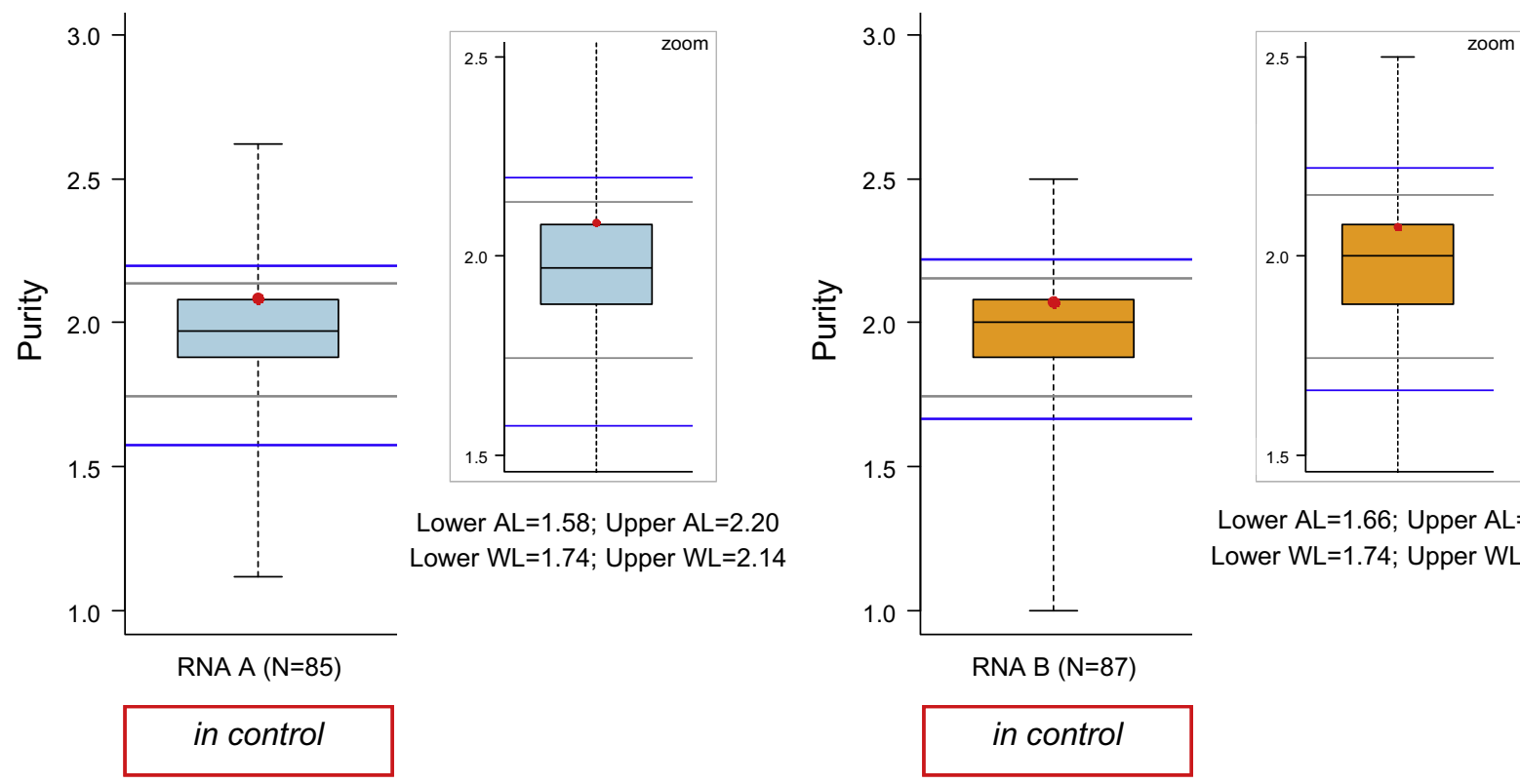

Lower $\mathrm{AL}=1.66$; Upper $\mathrm{AL}=2.22$ Lower $\mathrm{WL}=1.74$; Upper $\mathrm{WL}=2.15$

A.4. Your lab (๑) versus overall distribution - Quantity

In the figures the blue line represents the Action Limit (AL) and the gray line represents the Warning Limit (WL).

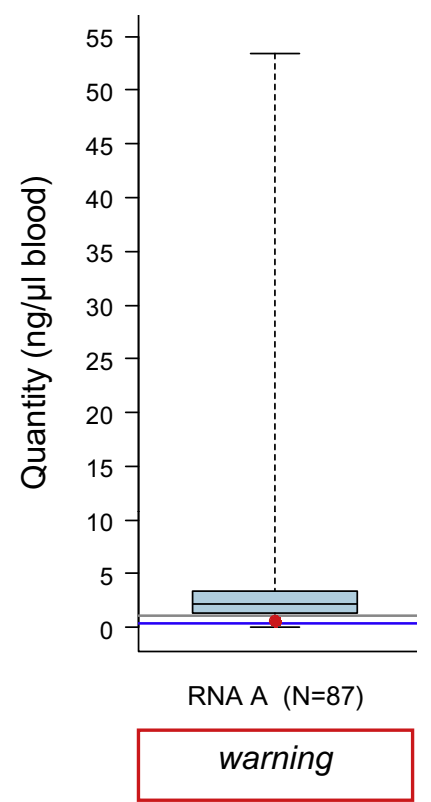

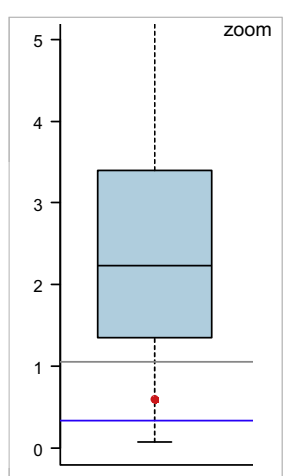

$\mathrm{AL}=0.34 ; \mathrm{WL}=1.06$

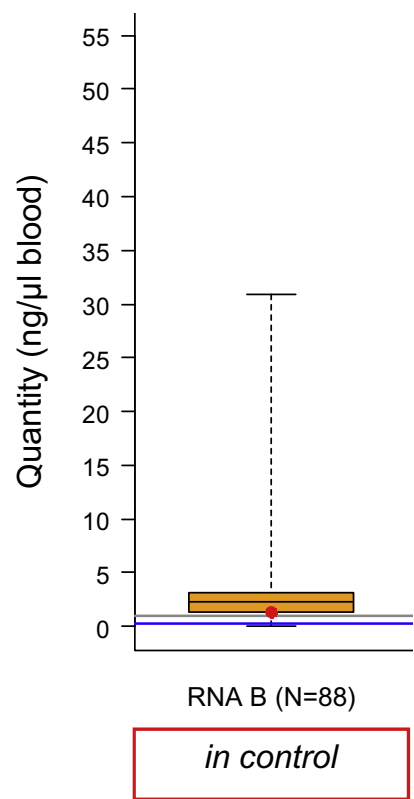

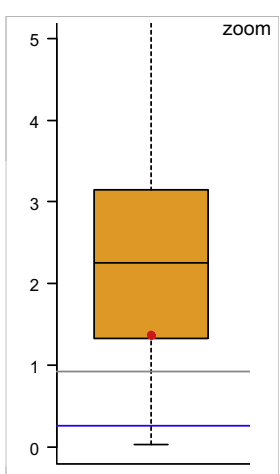

$A L=0.26 ; W L=0.92$ 


\section{Appendix B. Integrity of RNA A and RNA B}

B.1. Your lab (•) versus overall distribution - RIN number

In the figures the blue line represents the Action Limit (AL) and the gray line represents the Warning Limit (WL).

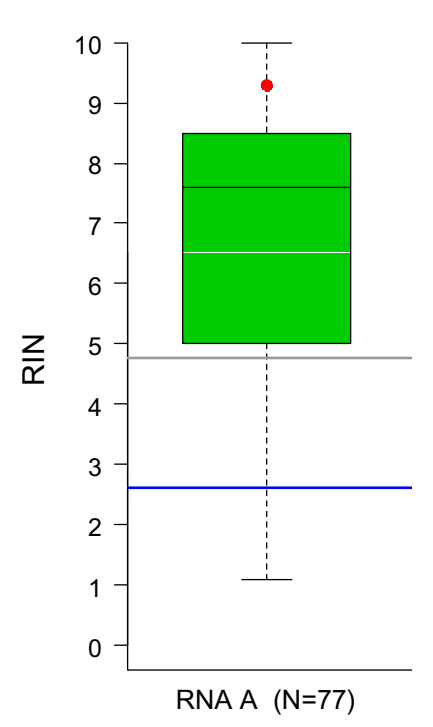

$A L=2.61 \quad W L=4.77$

in control

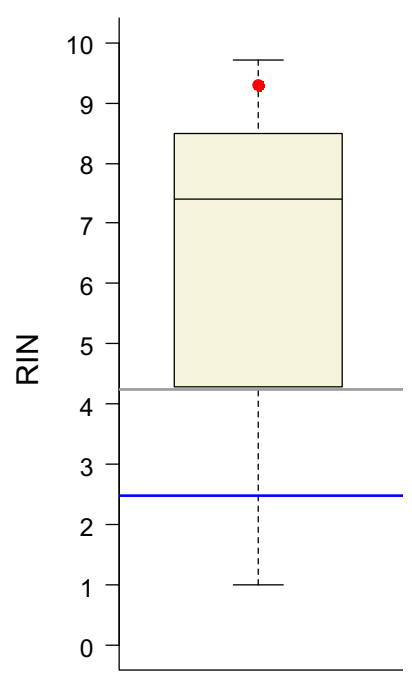

RNA B $(\mathrm{N}=78)$

$A L=2.49 \quad W L=4.25$

in control

\section{B.2. Electropherogram Agilent}
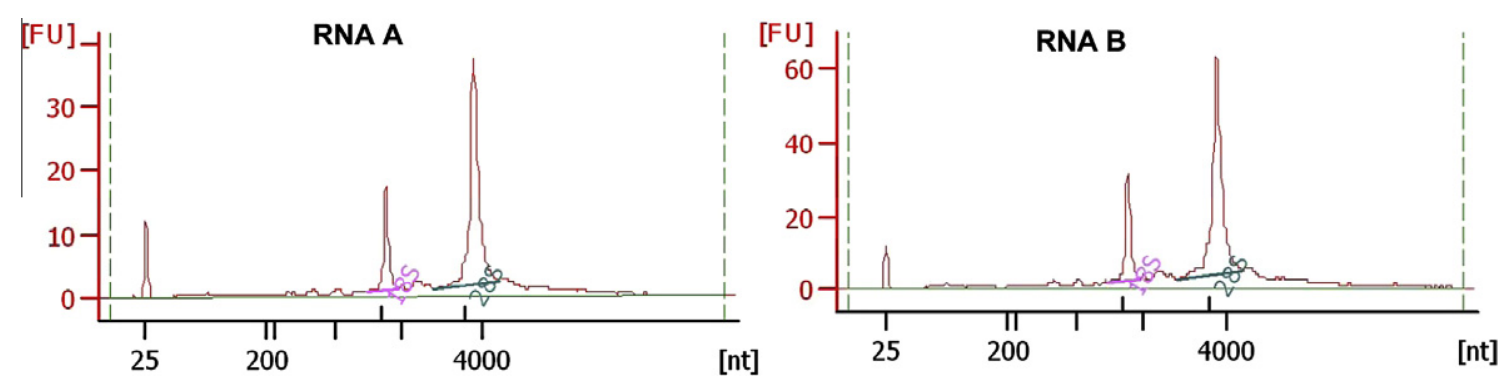


\section{Appendix C. Quantification of four genes by real-time PCR on RNA A and RNA B}

C.1. Your lab (•) versus overall distribution - RNA A

In the figures the blue lines represent the Action Limits (ALs) and the gray lines represent the Warning Limits (WLs).

C-FOS

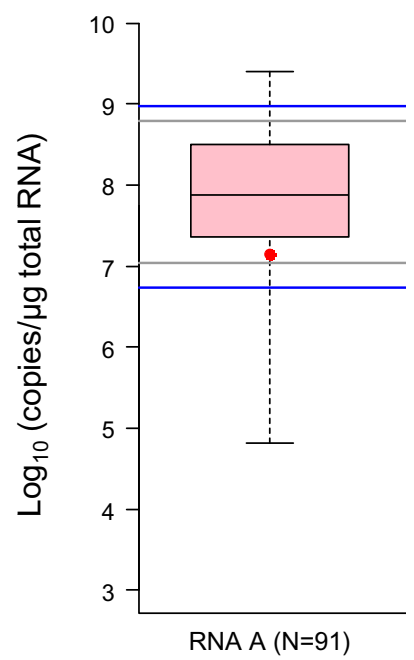

Lower $\mathrm{AL}=6.74$; Upper $\mathrm{AL}=8.98$ Lower $\mathrm{WL}=7.04$; Upper $\mathrm{WL}=8.80$
GAPDH

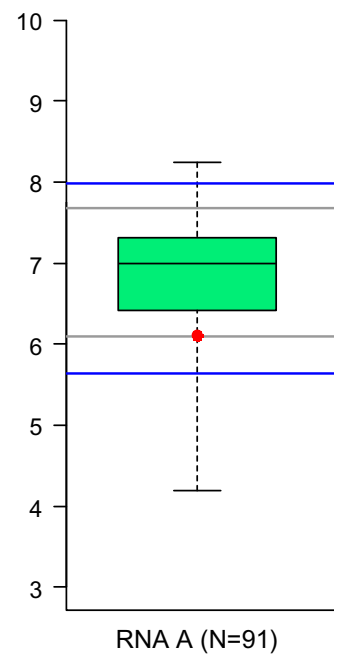

Lower $\mathrm{AL}=5.63$; Upper $\mathrm{AL}=7.99$ Lower $\mathrm{WL}=6.09$; Upper $\mathrm{WL}=7.68$
IL1b

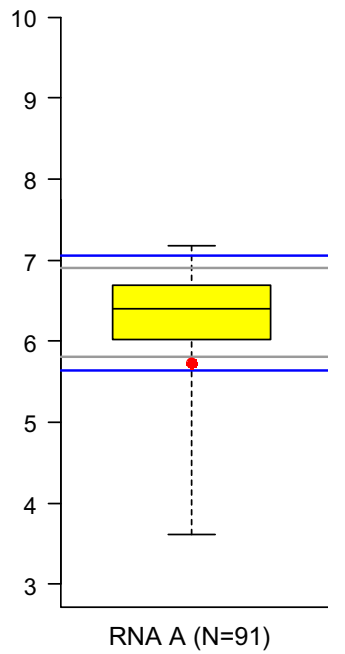

Lower $\mathrm{AL}=5.64$; Upper $\mathrm{AL}=7.06$ Lower $\mathrm{WL}=5.81$; Upper $\mathrm{WL}=6.90$

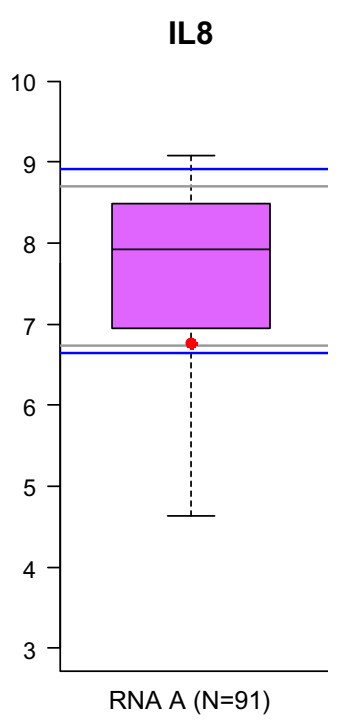

Lower $A L=6.64$; Upper $A L=8.91$ Lower $\mathrm{WL}=6.73$; Upper $\mathrm{WL}=8.70$
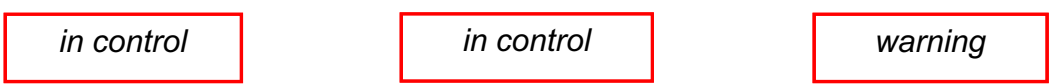

in control

\section{C.2. Your lab (•) versus overall distribution - RNA B}

In the figures the blue lines represent the Action Limits (ALs) and the gray lines represent the Warning Limits (WLs).

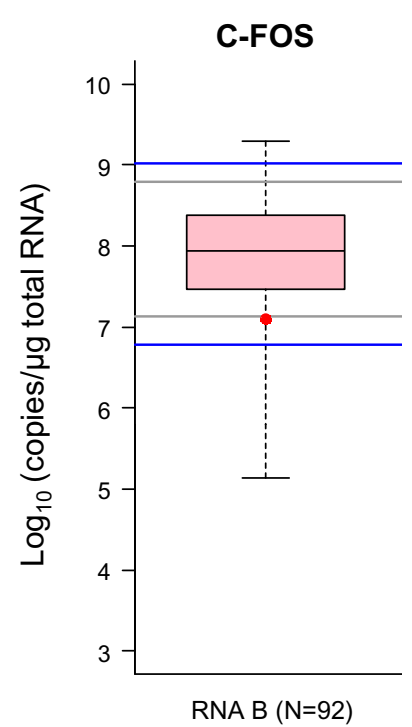

Lower $\mathrm{AL}=6.79$; Upper $\mathrm{AL}=9.02$ Lower $\mathrm{WL}=7.13$; Upper $\mathrm{WL}=8.79$

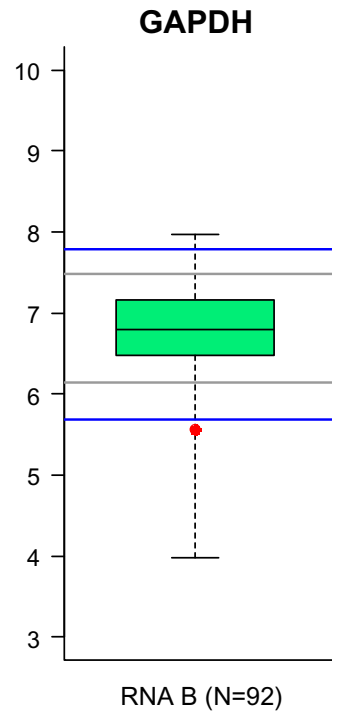

Lower $\mathrm{AL}=5.68$; Upper $\mathrm{AL}=7.78$ Lower $\mathrm{WL}=6.14$; Upper $\mathrm{WL}=7.48$
IL1b

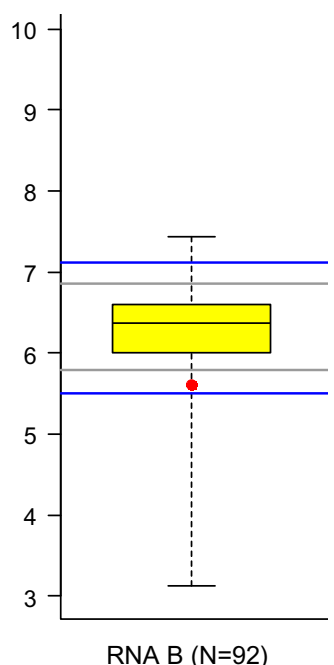

Lower $\mathrm{AL}=5.51$; Upper $\mathrm{AL}=7.11$ Lower $\mathrm{WL}=5.78$; Upper $\mathrm{WL}=6.85$
IL8

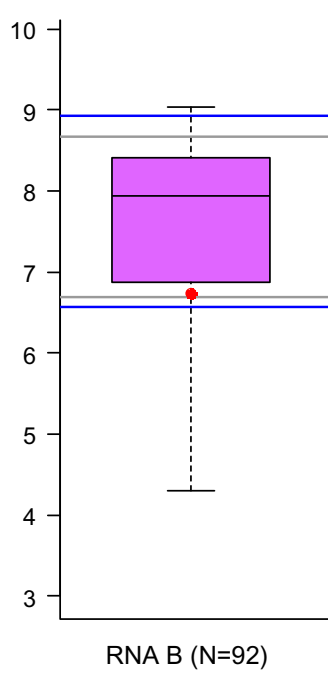

Lower $\mathrm{AL}=6.57$; Upper $\mathrm{AL}=8.92$ Lower $\mathrm{WL}=6.69$; Upper $\mathrm{WL}=8.67$ warning out of control

warning 


\section{Appendix D. Interferences in quantification of four genes by real-time PCR on RNA A and RNA B}

D.1. Your lab (•) versus overall distribution - RNA A

In the figures the two lines represent the two Kineret threshold for outliers identification: 5.99 (weak outlier) and 9.21 (strong outlier).
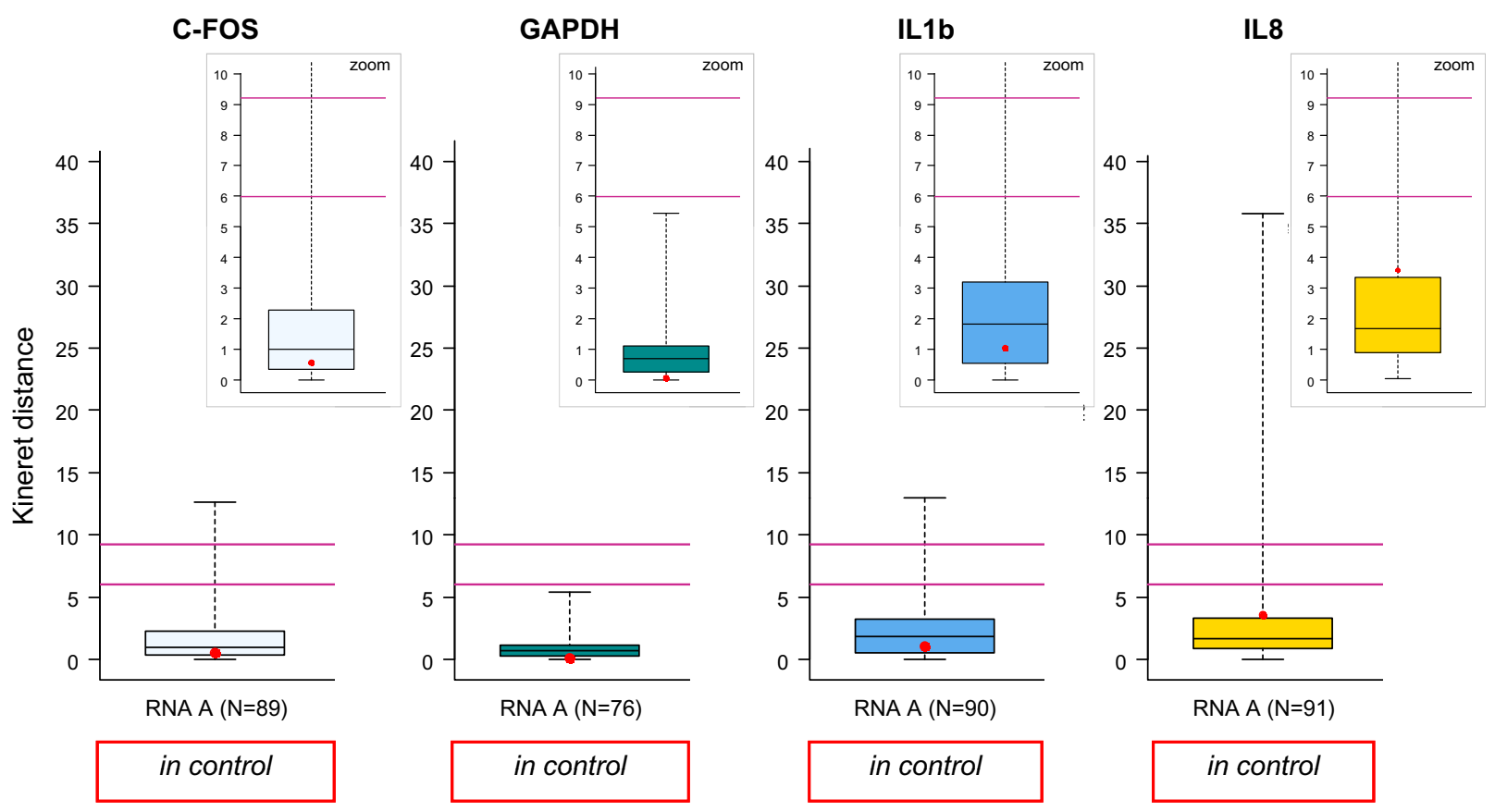

D.2. Your lab (•) versus overall distribution - RNA B

In the figures the two lines represent the two Kineret threshold for outliers identification: 5.99 (weak outlier) and 9.21 (strong outlier).
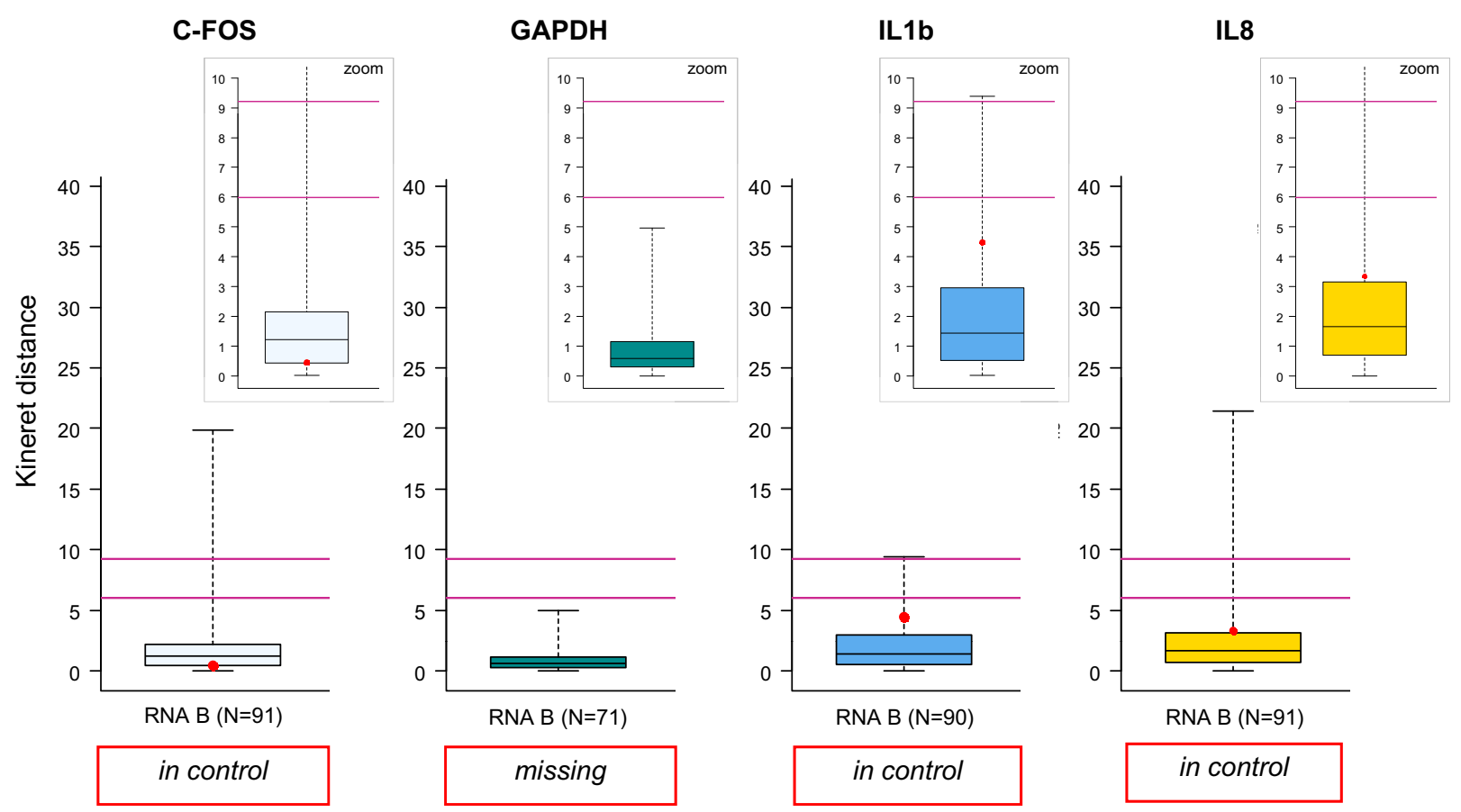


\section{Appendix E. Summary}

\begin{tabular}{|c|c|c|c|c|c|}
\hline & & Performa & & Missing & Comments \\
\hline RNA A - Purity & in control & & & & \\
\hline RNA B - Purity & in control & & & & \\
\hline RNA A - Quantity & & warning & & & \\
\hline RNA B - Quantity & in control & & & & \\
\hline RNA A — Integrity & in control & & & & \\
\hline RNA B - Integrity & in control & & & & \\
\hline RNA A - C-FOS quant & in control & & & & \\
\hline RNA A - GAPDH quant & in control & & & & \\
\hline RNA A - IL 1b quant & & warning & & & \\
\hline RNA A - IL8 quant & in control & & & & \\
\hline RNA B - C-FOS quant & & warning & & & \\
\hline RNA B - GAPDH quant & & & out of control & & \\
\hline RNA B - IL1b quant & & warning & & & \\
\hline RNA B - IL8 quant & in control & & & & \\
\hline RNA A - C-FOS interferences & in control & & & & \\
\hline RNA A - GAPDH interferences & in control & & & & \\
\hline RNA A - IL1b interferences & in control & & & & \\
\hline RNA A - IL8 interferences & in control & & & & \\
\hline RNA B - C-FOS interferences & in control & & & & \\
\hline RNA B - GAPDH interferences & & & & missing & $\begin{array}{l}\text { there isn't enought data for } \\
\text { kineret analysis }\end{array}$ \\
\hline RNA B - IL1b interferences & in control & & & & \\
\hline RNA B - IL8 interferences & in control & & & & \\
\hline
\end{tabular}

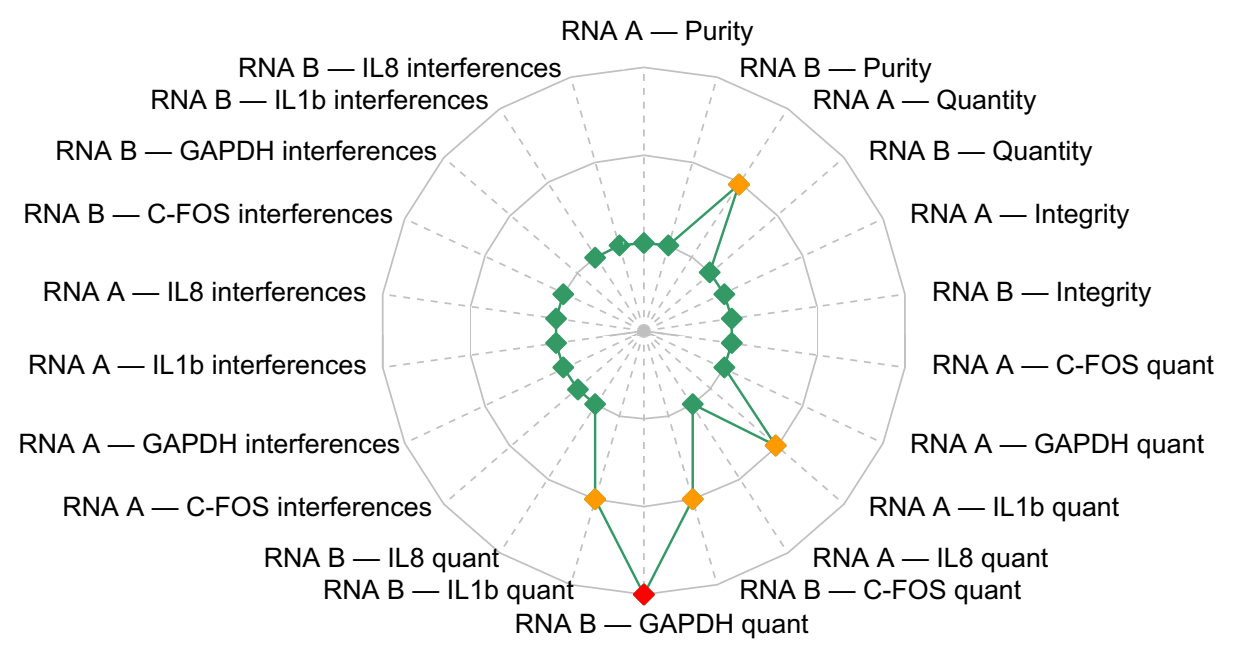

This report has been produced with the collaboration of the University of Florence (M.Pazzagli, S.Gelmini,

C.Orlando, L.Simi, F.Malentacchi), Fondazione IRCCS Istituto Nazionale dei Tumori of Milan (P.Verderio, S.Pizzamiglio, C.Ciniselli) and TATAA BIOCENTER (A.Tichopad). 


\section{Appendix A. Supplementary material}

Supplementary data associated with this article can be found, in the online version, at http://dx.doi.org/10.1016/j.ymeth. 2012.10.007.

\section{References}

[1] C. Nussbaumer, E. Gharehbaghi-Schnell, I. Korschineck, Forensic Sci. Int. 157 (2006) 181-186.

[2] R. Ovstebo, K. Lande, P. Kierulf, K.B.F. Haug, Clin. Chim. Med. 45 (2007) 171176.

[3] K. Günther, F. Malentacchi, P. Verderio, S. Pizzamiglio, C.M. Ciniselli, A. Tichopad, M. Kubista, R. Wyrich, M. Pazzagli, S. Gelmini, Clin. Chim. Acta 413 (2012) 779-786.

[4] S.A. Bustin, Methods 50 (2010) 217-226.

[5] L. Rainen, U. Oelmueller, S. Jurgensen, R. Wyrich, C. Ballas, J. Schram, C. Herdman, D. Bankaitis-Davis, N. Nicholls, D. Trollinger, V. Tryon, Clin. Chem. 48 (2002) 1883-1890.

[6] C. Härtel, G. Bein, M. Müller-Steinhardt, H. Klüter, J. Immunol. Methods 249 (2001) 63-71.

[7] A. Pahl, K. Brune, Blood 100 (2002) 1094-1095.

[8] S.J. Kim, D.J. Dix, K.E. Thompson, et al., Clin. Chem. 53 (2007) 1038-1045.
[9] C. Orlando, P. Verderio, R. Maatman, J. Danneberg, S. Ramsden, M. Neumaier, D. Taruscio, V. Falbo, R. Jansen, C. Casini-Raggi, F. Malentacchi, E. Marubini, S. Pizzamiglio, K. Vernelen, J.C. Libeer, V. Palicka, M. Pazzagli, Clin. Chem. 53 (2007) 1349-1357.

[10] B. Efron, R.J. Tibshirana, An Introduction to the Bootstrap, Chapman and Hall, London, 1993. $436 \mathrm{pp}$.

[11] B. Iglewicz, D.C. Hoaglin, How to Detect and Handle Outliers, ASCQ Quality Press, Milwaukee, WI, 1993.

[12] A. Tichopad, T. Bar, L. Pecen, R.R. Kitchen, M. Kubista, M.W. Pfaffl, Methods 50 (2010) 308-312.

[13] OECD Genetic Testing: a survey of Quality Assurance and Proficiency Testing, 2007, 134pp. ISBN-978-92-64-03201.

[14] R.M. Madej, Z. Cao, L. Hall, P.D. Neuwald, L.O. Williams, Proficiency Testing (External Quality Assessment) for Molecular Methods, Approved Guideline. CLSI document MM14-A, vol. 25, no. 24. Clinical and Laboratory Standards Institute, 2005, pp. 1-51.

[15] S.C. Ramsden, S. Daly, W.J. Eilenkeuser, G. Duncan, F. Hermitte, E. Marubini, M. Neumaier, C. Orlando, V. Palicka, A. Paradiso, M. Pazzagli, S. Pizzamiglio, P. Verderio, Clin. Chem. 52 (2006) 1584-1591.

[16] C.C. Raggi, P. Verderio, M. Pazzagli, E. Marubini, L. Simi, P. Pinzani, A. Paradiso, C. Orlando, Clin. Chem. Lab. Med. 43 (2005) 542-548.

[17] S. Fleige, M. Pfaffl, Mol. Asp. Med. 27 (2006) 126-139.

[18] S. Fleige, V. Walf, S. Huch, C. Prgomet, J. Sehm, M.W. Pfaffl, Biotechnol. Lett. 28 (2006) 1601-1613. 